\title{
Evaluation of DNA Markers Linked to Blast Resistant Genes, Pikh, Pit $(p)$, and Pita, for Parental Selection in Sri Lankan Rice Breeding
}

\author{
W.A.D. Jayawardana, G.A.U. Jayasekera ${ }^{1 *}$, R.L.C. Wijesundera ${ }^{1}$ \\ D M.N. Dissanayake ${ }^{2}$, S. D. S. S. Sooriyapathirana ${ }^{3}$, C.K. Weebadde ${ }^{4}$, K.L.N.S. Perera ${ }^{5}$ \\ K.R.D Gunapala ${ }^{6}$ and P. Hettige ${ }^{1}$
}

\author{
Department of Plant Sciences \\ Faculty of Science \\ University of Colombo \\ Colombo 03, Sri Lanka
}

\begin{abstract}
Rice blast, is a serious disease affecting rice, caused by a fungal pathogen Magnaporthe grisea (anarmorph - Pyricularia grisea). This paper summarizes the progress and the achievements made in detection of blast resistance genes in phenotypically evaluated, selected rice cultivars in Sri Lanka based on simple sequence repeats (SSR) DNA markers. In the present study blast pathogen was identified by morphological characters, molecular techniques which confirmed the identity as $\underline{M}$. grisea. Total of 34 rice varieties including several Sri Lankan rice varieties and IRRI recommended rice varieties were evaluated for blast resistance. Total of 17 varieties were susceptible to the fungal infection and 17 varieties remained resistant. Tetep, Bg359, Bg304, IR64, Bg352, Bg357 were found to be highly resistant to the rice blast disease, while LD125, Bg94/1, Bw267-3, Bw451, Bw400, H7, Bg34-6, H10, IRRI119 were highly susceptible. In marker genotyping, most of the highly resistant and resistant varieties demonstrated the presence of blast resistant Pita gene of variety Tetep and Pita gene was absent in the highly susceptible varieties. But Pita gene was absent in some of the resistant varieties like Bg300, Bg348 and Ptb33 and present in susceptible varieties H10, Bg276-5 and IR07F291. For polymorphism of Pikh gene most of the resistant varieties depicted the band lengths of 161-171bp. Susceptible varieties gave the band length of $151 \mathrm{bp}$. According to results of marker genotyping with Pit(p) blast resistant gene, the resistant varieties gave a band length of $117 \mathrm{bp}$ while susceptible varieties produced the band length of $111 \mathrm{bp}$. Hence, resulted polymorphism findings can be used in future studies to differentiate the resistant and susceptible varieties.
\end{abstract}

Keywords: F2 population, Magnaporthe grisea (anarmorph - Pyricularia grisea), marker genotyping, phenotypic screening, rice blast resistance.

\footnotetext{
Department of Plant Science, Faculty of Science, University of Colombo, Colombo 03, Sri Lanka.

Ministry of Agriculture, Battaramulla, Colombo, Sri Lanka

Department of Molecular Biology and Biotechnology, Faculty of Science, University of Peradeniya, Sri Lanka.

4 Department of Horticulture and Institute of International Agriculture, Michigan State University, United State of America.

Genetech molecular diagnostics and school of gene technology, Colombo 8, Sri Lanka.

6 Rice Research and Development Institute, Batalagoda, Ibbagamuwa, Kurunagala, Sri Lanka

* Corresponding author: jayasekeraanil@yahoo.com
} 


\section{INTRODUCTION}

Rice blast, caused by the fungal pathogen Magnaporthe grisea (anamorph- Pyricularia grisea) is a serious disease affecting rice growing regions in Sri Lanka and in the world (Rossman et al., 1990). The disease has been reported in over 85 countries across the world. Blast generally considered as the most destructive disease of rice due to its widespread distribution and potential to cause up to $50 \%$ yield loss when conditions are favourable for its occurrence (Skamnioti and Gurr, 2009). Rice blast is estimated to cause production losses amounting to US\$ 55 million each year in South and Southeast Asia. The fungus causes lesions on leaves, stems, peduncles, panicles, seeds, and even roots (Mithrasena et al., 2012). The fungus can infect the rice from seedling stage through maturity. Other grasses, including crabgrass, are infected with closely related fungi of Magnaporthe family (Magnaporthe grisea, Magnaporthe poae, Magnaporthe rhizophila and Magnaporthe salvinii etc.), which causes nearly identical symptoms on their respective hosts (Sharma et al., 2002). Rice blast is controlled usually by use of fungicides that results in high production costs and environmental pollution (Ghazanfar et al., 2009).

Breeding of rice varieties with effective and sustained resistance to blast is considered as the most economical and environmentally sound strategy for management of rice blast (Mackill and Bonman, 1992). In Sri Lanka traditional rice varieties grown prior to 1950' s were highly susceptible to blast disease. Therefore, incorporation of blast resistance into new varieties through rice hybridization was incepted and resistant varieties were released. However the rapid breakdown of varietal resistance to blast has been possible and appears to be a result of emergence of virulent races within pathogen population and it indicates the narrow genetic diversity for blast resistance within these varieties that have been cultivated over the years in Sri Lanka (Dissanayake, 1995).Therefore, rice breeders have directed their efforts, towards enhancing durable blast resistance in new improved rice varieties via use of genetically diverse blast resistance sources. To breed rice varieties with more durable blast resistance, multiple resistance genes with qualitative and quantitative gene effect must be incorporated into individual rice varieties. Conventional methods currently deployed by rice breeders in Sri Lanka for identification blast resistance from rice germplasm and progenies in breeding programs are based on phenotypic screening (Jayawardana et al., 2013). However phenotypic screening is influenced by environmental conditions and is cumbersome to detect and expensive to practice, because it requires the use of large field spaces. This necessitates the exploration of more efficient selection and breeding strategies than those currently in practice. Identifying blast resistant genes with DNA markers that are tightly linked to them, which can act as molecular tags will save money and time (Joshi et al., 2009). Upon identification of polymorphic microsatellite markers closely linked to desirable characters marker aided selection (MAS) can be performed for selection of sources of resistance in early segregating generations and at early stages of plant development. These DNA marker tags can be used for direct identification of resistant genes when they are transferred from one varietal background to another during breeding programs (Fijellstorm et al., 2002). The recent achievements made in DNA marker aided technology may provide new ways for developing durable blast resistant varieties with desirable traits in rice.

This paper summarize the progress and achievement made in detection of blast resistance genes in phenotypically evaluated, selected rice cultivars in Sri Lanka based on simple sequence repeats (SSR) DNA markers which help in developing durable blast resistance cultivars that can overcome destructive rice blast disease in Sri Lanka. In this research, to identify polymorphism in Sri Lankan rice germplasm, simple sequence repeats markers (RM206, RM246) and gene marker (YL87/YL155) were incorporated based on a genealogy 
study that was conducted on the highly blast resistant variety Tetep by us prior to this study. It identified several IR varieties such as IR64, IR24, IR8, IR36 and mainly a Vietnamese variety Tetep (Sharma et al., 2012) contributed blast resistant genes to Sri Lankan germplasm. The markers RM206, RM246 and YL87/YL155 are linked to the blast resistant genes, Pita, Pit $(p)$ and Pikh respectively in variety Tetep (McCouch et al., 1997). The ultimate objective of present study was to report the genetic basis of Sri Lankan rice germplasm using these genetic markers that will enable the rice breeders to have a better overview on blast resistance when transferring genes from one varietal background to another in future marker aided breeding program in Sri Lanka.

\section{MATERIALS AND METHODS}

\section{Isolation and identification of rice blast fungus}

The infected leaves of rice plants were cut in to small pieces $(0.5-1 \mathrm{~cm})$ and kept on a moist filter paper in petri plates and incubated for one day at room temperature. Blast lesions were carefully observed under a light microscope and fungal spores were identified and transferred into a specific medium called Rice Polish Agar (RPA) that enhances the fungal sporulation (Mithrasena et al., 2012). The fungus was purified by sub culturing on PDA and RPA medium. Morphological characteristics of the fungus were observed under the light microscope.

For the molecular identification, fungal DNA was extracted using Promega Wizard DNA extraction kit and subjected to PCR using forward and reverse primers for internally transcribed spacers (ITS1) and (ITS4) respectively (Guillamon et al., 1998). PCR products were size separated in $2 \%$ agarose gel. DNA bands were excised and purified using Promega PCR product agarose gel purification kit. Purified DNA was sequenced using a Big Dye terminator v3.1 cycle sequencing kit and an ABI-310 Genetic Analyzer. The obtained sequence was entered to BLAST program and BLASTn analysis was carried out.

\section{Phenotypic screening of rice varieties}

Total 34 rice varieties including Sri Lankan rice varieties and International Rice Research Institute (IRRI) recommended rice varieties were obtained from Rice Research and Development Institute (RRDI), Bathalagoda. The selected rice varieties were established in the field of upland blast nursery at Bathalagoda according to the complete randomized design Fig. 1. Three replicates for each rice variety were maintained. A total of 144 rice lines including Pachchaiperumal rice lines were included. All these rice lines were surrounded by a highly susceptible Pachchaiperumal rice line in order to enhance the level of infection and better scoring. Prior to the infection, nitrogen level of the field was increased by adding nitrogen fertilizer to the established field for the proper establishment of the disease (Dissanayake, 1995). 


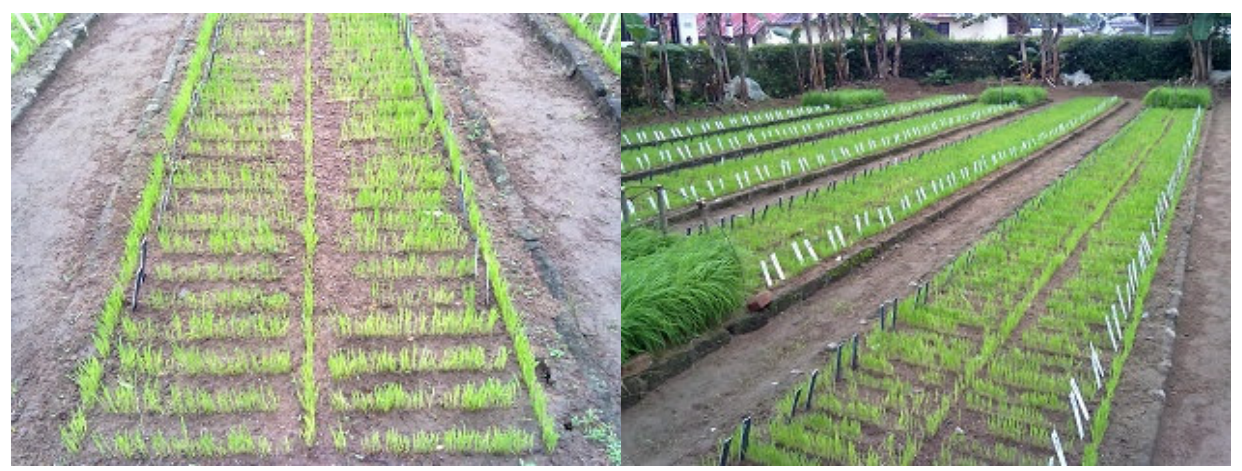

Fig. 1. Established rice field for scoring blast disease

After two weeks of the field establishment of rice varieties, infection was conducted by using both dry leaf spore suspension of fungus $M$. grisea and blast infected leaves of Pachchaiperumal plants. Infection was carried out two times per day. The required high humidity and moisture level were maintained by covering the entire field at night to create moisture chambers which favours the fungal growth. At the day time, the covers were removed and the entire field was exposed to the sunlight. The infection was continued till the typical blast lesions appeared in the rice leaves. All rice lines were scored by using IRRI stipulated standard scoring system. Based on the scoring system the rice varieties were grouped in to six major classes such as highly resistant, resistant, mildly resistant, highly susceptible, susceptible, mildly susceptible (IRRI, 1996). Lesion shape, colour, size, number of lesions, percentage of the lesions per leaves were taken as measurements indicated in Table 1 . The mean values obtained for each variety were used to determine the susceptibility and resistivity of rice varieties.

Table 1. Standard evaluation system for rice blast, IRRI, 1996

\begin{tabular}{|c|c|}
\hline \multicolumn{2}{|c|}{ SCALE (for blast nursery) } \\
\hline 0 & No lesions observed \\
\hline & $\begin{array}{l}\text { Small brown specks of pin-point size or larger brown specks without sporulating } \\
\text { centre }\end{array}$ \\
\hline & $\begin{array}{l}\text { Small roundish to slightly elongated, necrotic gray spots, about } 1-2 \mathrm{~mm} \text { in diameter, } \\
\text { with a distinct brown margin }\end{array}$ \\
\hline & $\begin{array}{l}\text { Lesion type is the same as in scale } 2 \text {, but a significant number of lesions are on the } \\
\text { upper leaves }\end{array}$ \\
\hline & $\begin{array}{l}\text { Typical susceptible blast lesions } 3 \mathrm{~mm} \text { or longer, infecting less than } 4 \% \text { of the leaf } \\
\text { area }\end{array}$ \\
\hline 5 & Typical blast lesions infecting $4-10 \%$ of the leaf area \\
\hline 6 & Typical blast lesions infection $11-25 \%$ of the leaf area \\
\hline 7 & Typical blast lesions infection $26-50 \%$ of the leaf area \\
\hline 8 & Typical blast lesions infection $51-75 \%$ of the leaf area and many leaves are dead \\
\hline & More than $75 \%$ leaf area affected \\
\hline
\end{tabular}




\section{Marker genotyping of phenotypically evaluated rice varieties}

Rice varieties which were phenotypically evaluated (except $\mathrm{H} 4$ and $\mathrm{Bg} 96-3$ rice varieties) were used in the marker genotyping. All varieties were grown in pots and maintained for a period of 21 days at plant house in the Department of Plant Science, University of Colombo. Prior to DNA extractions leaves of all varieties were collected, preserved in liquid $\mathrm{N}_{2}$ and stored at $-80^{\circ} \mathrm{C}$ temperature in Genetech Institute, Colombo (McCouch et al.,1997). DNA was extracted using CTAB method (Doyle and Doyle, 1987). Two SSR markers linked to the blast resistant genes in variety Tetep; RM206 (linked to the gene Pikh) and RM246 (linked to the gene Pit $(p)$ ) and one gene specific marker YL155/YL87 (linked to the gene Pita) were used for genotyping. Agarose and polyacrylamide gel electrophoresis were incorporated for the size separation of PCR products (Joshi et al., 2009).

\section{PCR amplification}

PCR was performed in $25 \mu 1$ reaction volumes in with Gene Amp PCR system 9600, Perkin Elmer, USA. PCR mix was contained $2.5 \mu \mathrm{l}$ of $10 \mathrm{X}$ buffer containing $\mathrm{MgCl}_{2}$ (Thermo Scientific 10X Dream Taq Buffer), $2.5 \mu 1$ of $3.5 \mathrm{mM}$ dNTP, $3.0 \mu 1$ from $2.5 \mu \mathrm{M}$ of primer mixture Table 2, $0.2 \mu 1$ of $5 \mathrm{U} / \mu 1$ Taq DNA polymerase and $12.8 \mu 1$ of sterile water. Each master mixture was prepared by using multiples of above recorded reagent volumes relevantly to the number of PCR. $21 \mu 1$ of the PCR master mixture was added to $4 \mu 1$ of DNA in PCR tube and the reaction was performed.

Table 2. Primer sequences

\begin{tabular}{llll}
\hline Gene & $\begin{array}{l}\text { Linked } \\
\text { marker }\end{array}$ & Forward primer & Reverse primer \\
\hline Pikh & $R M 206$ & CCCATGCGTTTAACTATTCT & CGTTCCATCGATCCGTATGG \\
Pit $(p)$ & $R M 246$ & GAGCTCCATCAGCCATTCAG & CTGAGTGCTGCTGCGACT \\
Pita & $Y L 155 / Y L$ & YL155:AGCAGGTTATAAGCTAG & YL87:CTACCAACAAGTTCATC \\
& 87 & GCC & AAA \\
\hline
\end{tabular}

\section{RESULTS AND DISCUSSION}

\section{Fungal isolation and molecular identification}

Rice blast fungus was isolated and purified using RPA medium. Fungus appeared gray ash colour mycelia and concentric rings on PDA and RPA medium as shown in Fig. 2. Typical hyaline, three septate fungal spores were observed as shown in Fig. 3. The results obtained in this study are in accordance with previous research reports published on the isolation of Magnaporthe (Mithrasena et al., 2012).

Analysis of DNA sequences using (ITS1and ITS4 primers using amplified DNA sequences) BLAST confirmed the identity of blast fungus which was $99 \%$ identical to M. gisea and it was used for the inoculation process. 

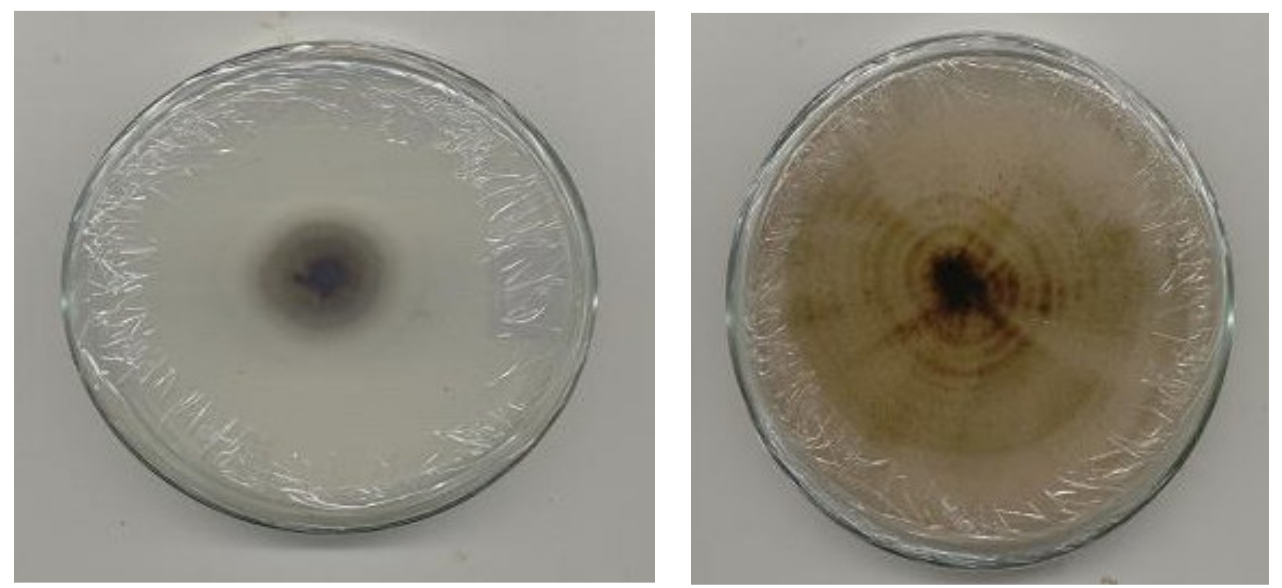

Fig. 2. Morphology of M. grisea in PDA and RPA
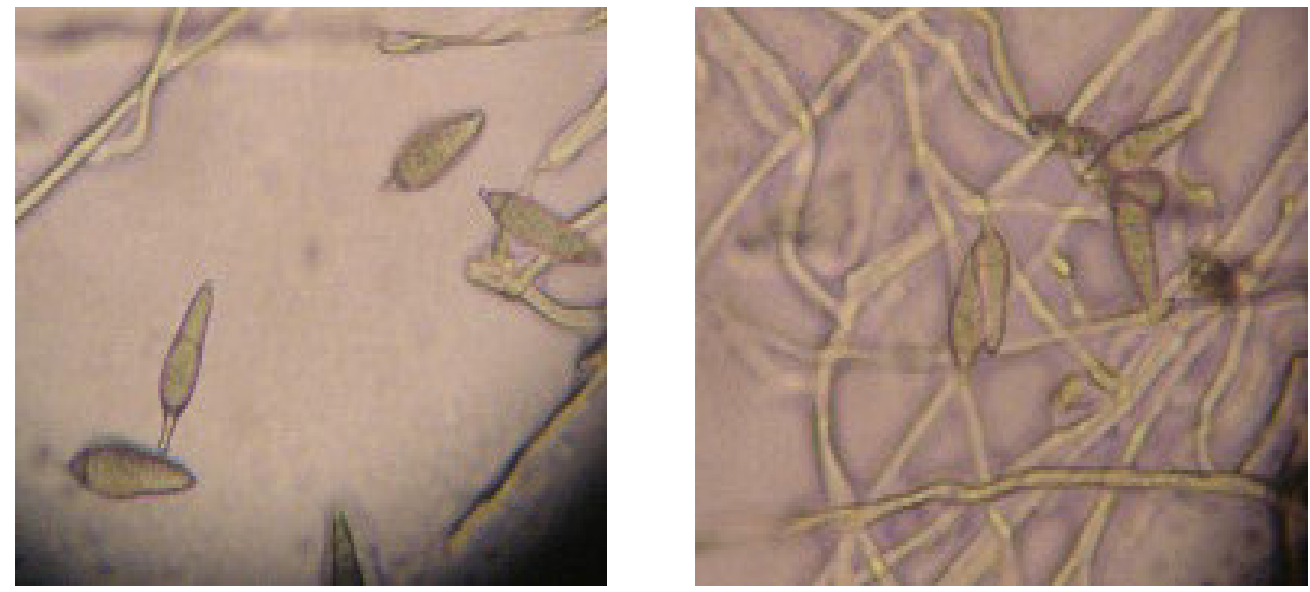

Fig. 3. Typical three septate, fusiform, hyaline spores of $M$. grisea

\section{Phenotypic screening of rice varieties}

Out of 34 varieties screened 17 varieties were susceptible to the fungal infection, while rest of the varieties remained resistant to the rice blast. Tetep, Bg359, Bg304, IR64, Bg352 and $\mathrm{Bg} 357$ varieties were highly resistant to the rice blast disease. LD125, Bg94/1, Bw267-3, $\mathrm{Bw} 451, \mathrm{Bw} 400, \mathrm{H} 7, \mathrm{Bg} 34-6, \mathrm{H} 10$ and IRRI119 varieties were highly susceptible as indicated in Table 3. Most of the resistant varieties have retained their resistance over the years while some of them (H7, H10, Bw451, Bw78, Bw400, Bw267-3) have lost their resistance in comparison with the previous study (Rajapakse et al., 2000).

All 34 varieties were clustered in to six groups (highly resistant, resistant, mildly resistant, mildly susceptible, susceptible and highly susceptible). Tetep was found to be highly resistant and Pachchaiperumal found be highly susceptible as shown in Fig. 4. 
Jayawardana et al.

Table 3. Rice varietal groups based on blast resistance

\begin{tabular}{|c|c|}
\hline Group & Rice varieties \\
\hline Highly resistant & Tetep, Bg304, Bg359, IR64, Bg352, Bg357 \\
\hline Resistant & $\begin{array}{l}\mathrm{Bg} 360, \mathrm{H} 4, \text { Swarna sub, Bg300, Bg96-3, Bg403, Ptb33, } \\
\mathrm{Bg} 407, \mathrm{Bg} 34-8, \mathrm{Bg} 96-741\end{array}$ \\
\hline Moderately resistant & Engatek \\
\hline Moderately susceptible & None \\
\hline Susceptible & $\begin{array}{l}\text { Bg450, Bg276-5, Ld66, IR07F290, Bw78, IR07F291 } \\
\text { Sambamashuri }\end{array}$ \\
\hline Highly susceptible & $\begin{array}{l}\text { Pachchaiperumal, LD125, Bg94-1, Bw267-3, Bw451, } \\
\text { Bw400, H7, Bg34-6, H10, IRRI119 }\end{array}$ \\
\hline
\end{tabular}

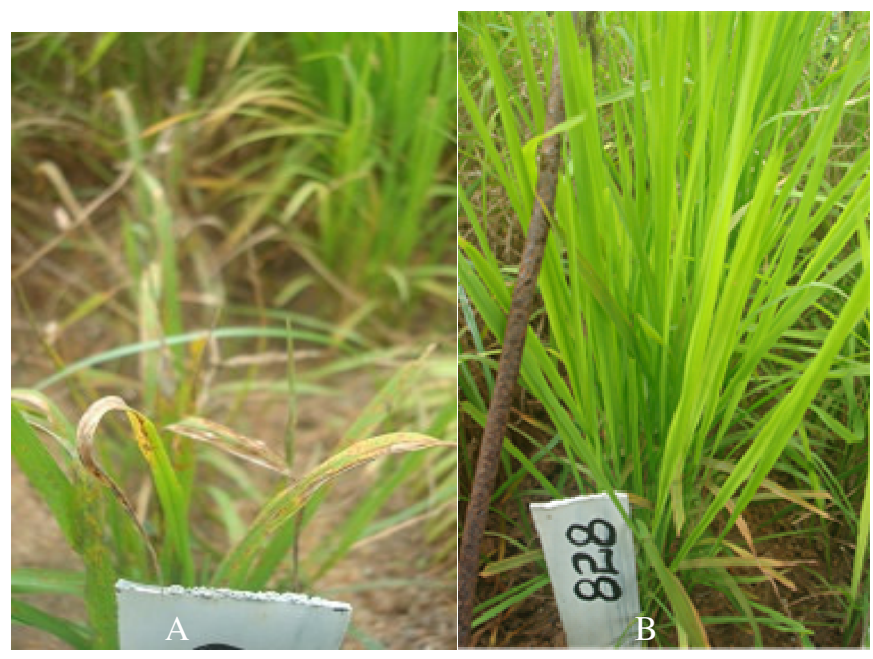

Fig. 4. Highly susceptible Pachchaiperumal (A), Highly resistant Tetep (B)

The blast resistance scores of all the rice varieties are indicated in Fig. 5. 


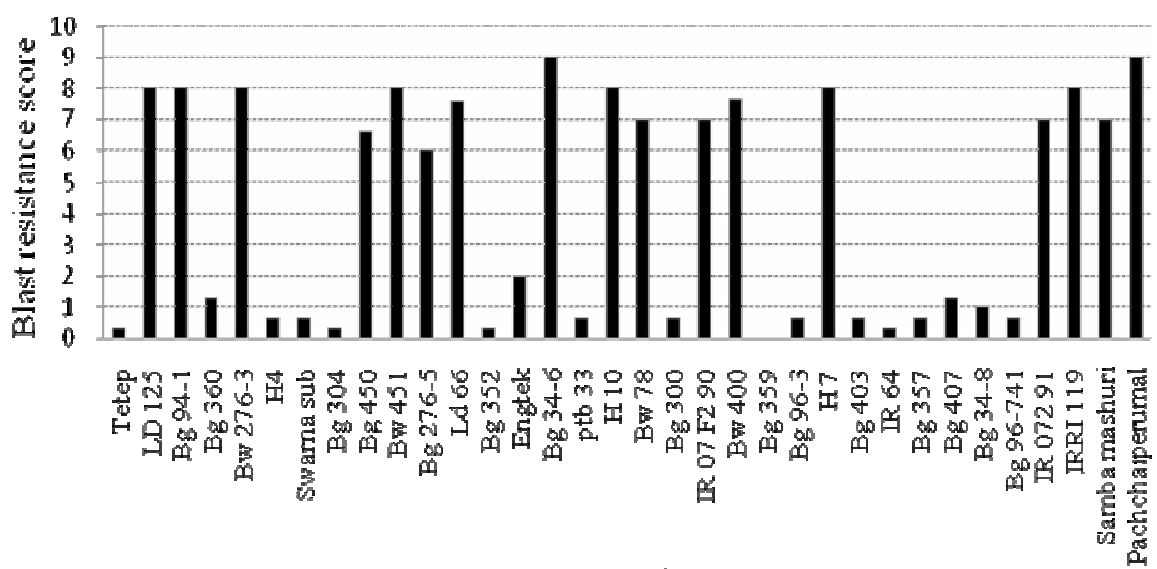

Ruce variety-

Fig. 5. Blast resistance scores of rice varieties

\section{DNA marker analysis}

\section{RM206 marker polymorphism linked to the gene Pikh}

The expected band length observed for SSR marker RM206 was 147bp.Most of the resistant varieties depicted the band lengths of (161-171bp) for RM206 and susceptible varieties given the band length of $151 \mathrm{bp}$. The marker polymorphisms which was prominent for Pikh blast resistant gene clearly differentiated some of the resistant and susceptible varieties Table 4. Hence this information can be used in future studies to identify these resistant and susceptible varieties based on above polymorphism. The other resistant varieties like Bg352, $\mathrm{Bg} 360, \mathrm{Bg} 300$ and $\mathrm{Bg} 357$ were given average band length of 151-155bp and the varieties Swarnasub-1 and Bg407 did not produce clear bands. While rest of the susceptible varieties Ld66, IR07F290, Bw78, IR07F291, Sambamashuri, Bg94/1, H10 and Bw267-3 yielded band lengths of (169-177bp) and the varieties Bw451 and Ld125 did not produce any band.

\section{RM246 marker polymorphism linked to the gene Pit (p)}

Expected band length observed for SSR marker RM246 was 115bp.The resistant varieties produced a band having a length of $117 \mathrm{bp}$ while susceptible varieties gave a band of $111 \mathrm{bp}$ as indicated in Table 4. Rest of the resistant varieties such as Tetep, Bg357, IR64, Swarnasub1, Bg300, Bg359 and Bg96-741 did not produce clear bands and the varieties Ptb33 and Bg352 produced a band of $111 \mathrm{bp}$. The other susceptible varieties such as Ld125, IRRI119 and Bw267-3 produced a 117bp band while susceptible varieties IR07F291, Bw78, IR07F290, Bg94/1, Bg34-6 and H7) did not produce any band.

\section{YL87/YL155 Marker Polymorphism Linked to the Gene Pita}

Most of the highly resistant and resistant varieties demonstrated the presence of blast resistant Pita gene of variety Tetep as indicated in Table 4. The Pita gene was absent in the highly susceptible and susceptible varieties. However Pita gene was also absent in some of the resistant varieties like $\mathrm{Bg} 300, \mathrm{Bg} 348$ and Ptb33, which indicates the idea of presence of 
some other blast resistant gene contributing to their blast resistance. Some of the susceptible varieties were shown the presence of Pita gene such as H10, Bg276-5 and IR07F291. Since this marker has been designed to amplify a specific region within the sequence of dominant Pita gene, presence of $1000 \mathrm{bp}$ long YL155/YL87 amplicon may directly provide evidence to prove that the respective cultivar holds the gene of interest.

According to previous reports the resistance of these varieties were broken recently (Dissanayake, 1995), which indicates the presence of single gene cannot be overcome virulent pathogens and their narrow genetic diversity made them susceptible to blast races (varieties H10, IR07F291 and Bg276-5). The same research findings described Bg276-5 was a blast resistant variety by the time of release and lost such resistance by 1989/1990. Similarly H10 was also blast resistant in 1958, at the time of first release and later subjected to a resistant breakdown. Hence even with the presence of Pita gene in the genomes the cultivars may susceptible to $M$. grisea pathotypes due to environmental or physiological conditions (Jayawardana et al., 2013). This would clarify the conflict of having dominant Pita gene in currently susceptible varieties Bg276-5, IR07F291 and H10. In addition locating Pita and Pita ${ }^{2}$ genes in the centromeric region of the $12^{\text {th }}$ chromosome of the rice genome have been suppressed the recombination between two genes. According to Bryan et al. (2000) and Shikari et al. (2013), Pita gene may tightly linked with or allelic to Pita ${ }^{2}$ and share same set of YL markers. The only difference of these genes is the performance of blast resistance towards different $M$. grisea isolates. Thus, there may be a significant chance for the existence Pita $^{2}$ gene by YL155/YL87 marker instead of Pita. So, this might also be a possible cause for amplification of 1000bp fragment in Bg276-5, H10 and IR07F291 which had been identified as blast susceptible varieties. Furthermore, the isolates used to screen the blast resistance or susceptibility status of cultivars may be virulent against the particular gene thus the cultivars may have been categorized as susceptible. And Shikari et al. (2013) states, there is a possibility of inhibiting the blast resistance triggered by resistance genes with the actions of other genic regions. Therefore these reasons might be possible facts for above mentioned varieties to be blast susceptible even they demonstrated positive amplification with Pita gene marker.

Overall suggestion is that the phenotypic data on blast resistance of evaluated Sri Lankan rice varieties were verified with these DNA marker data. It is important to use these marker data for identification of blast resistance lines in Sri Lankan rice breeding programs. It is also significantly important in direct selection of resistant genes when they are transferred from one varietal background to another for producing durable blast resistant varieties.

Table 4. Marker alleles for three genes, Pikh, Pit(p), and Pita

\begin{tabular}{lcccc}
\hline Variety & $\begin{array}{c}\text { Disease } \\
\text { reaction }\end{array}$ & $\begin{array}{c}\text { RM206 } \\
\text { (Pikh) } \\
\text { (allele size in } \\
\text { bp) }\end{array}$ & $\begin{array}{c}\text { RM246 } \\
\text { (Pitp) } \\
\text { (allele size in } \\
\text { bp) }\end{array}$ & $\begin{array}{c}\text { YL155/YL87(Pita) } \\
\text { *(Presence=P, } \\
\text { Absence=A } \\
\text { of allele) }\end{array}$ \\
\hline Tetep & HR & 169 & - & $\mathrm{P}$ \\
Bg304 & HR & 171 & 117 & $\mathrm{P}$ \\
Bg359 & HR & 171 & - & $\mathrm{P}$ \\
IR64 & HR & 171 & - & $\mathrm{P}$ \\
Bg352 & HR & 151 & 111 & $\mathrm{P}$ \\
Bg357 & HR & 155 & - & $\mathrm{P}$ \\
\hline
\end{tabular}




\begin{tabular}{|c|c|c|c|c|}
\hline Variety & $\begin{array}{l}\text { Disease } \\
\text { reaction }\end{array}$ & $\begin{array}{c}\text { RM206 } \\
(\text { Pikh }) \\
\text { (allele size in } \\
\text { bp) }\end{array}$ & $\begin{array}{c}\text { RM246 } \\
\text { (Pitp) } \\
\text { (allele size in } \\
\text { bp) }\end{array}$ & $\begin{array}{c}\text { YL155/YL87(Pita) } \\
*(\text { Presence=P, } \\
\text { Absence=A } \\
\text { of allele) }\end{array}$ \\
\hline $\mathrm{Bg} 360$ & $\mathrm{R}$ & 151 & 117 & $\mathrm{P}$ \\
\hline Swarnasubl & $\mathrm{R}$ & - & - & $\mathrm{P}$ \\
\hline $\mathrm{Bg} 300$ & $\mathrm{R}$ & 151 & - & A \\
\hline $\mathrm{Bg} 403$ & $\mathrm{R}$ & 169 & 117 & $\mathrm{P}$ \\
\hline Ptb33 & $\mathrm{R}$ & 169 & 111 & A \\
\hline Bg407 & $\mathrm{R}$ & - & 117 & $\mathrm{P}$ \\
\hline Bg34-8 & $\mathrm{R}$ & 169 & 117 & A \\
\hline Bg96-741 & $\mathrm{R}$ & 169 & - & $\mathrm{P}$ \\
\hline Engatek & $\mathrm{R}$ & 169 & 117 & $\mathrm{P}$ \\
\hline $\mathrm{Bg} 450$ & S & 151 & 111 & A \\
\hline Bg276-5 & S & 151 & 111 & $\mathrm{P}$ \\
\hline Ld66 & S & 169 & 111 & A \\
\hline IR07F290 & S & 169 & - & A \\
\hline Bw78 & $S$ & 177 & - & A \\
\hline IR07F291 & S & 171 & - & $\mathrm{P}$ \\
\hline Sambamashuri & S & 169 & 113 & A \\
\hline LD125 & HS & - & 117 & A \\
\hline Bg94/1 & HS & 169 & - & A \\
\hline Bw267-3 & HS & 171 & 117 & A \\
\hline Bw451 & HS & - & 111 & A \\
\hline Bw400 & HS & 151 & 111 & A \\
\hline $\mathrm{H} 7$ & HS & 151 & - & A \\
\hline IRRI119 & HS & 155 & 117 & A \\
\hline H10 & HS & 169 & 111 & $\mathrm{P}$ \\
\hline Bg34-6 & HS & 151 & - & A \\
\hline Pachchaiperumal & HS & 151 & 111 & A \\
\hline
\end{tabular}

Note: P- Presence, A- Absence

\section{CONCLUSIONS}

The blast fungus $M$. grisea (anamorph- Pyricularia grisea) was identified using molecular based techniques and sequence alignments data showed that the strain used in the present study was $99 \%$ similar to $M$. grisea. Out of 34 rice varieties screened in the phenotypic screening, 17 varieties were found to be susceptible to the pathogen and rests of the varieties were remained resistant. While some of the varieties have lost their blast resistance after few years of cultivation in comparison with the previous study (varieties H7, H10, Bw451, Bw78, Bw400 and Bw267-3). This appears to be a result of emergence of virulent races within pathogen population and narrow genetic diversity of these varieties for blast disease. Genetic basis of blast resistance in Sri Lankan rice germplasm was identified by the marker genotyping process performed with the SSR markers belong to major blast resistance genes [Pita, Pikh and Pit $(p)$ ] which verified the phenotypic screening made prior to genotyping. Hence these polymorphism findings can be used in future studies to differentiate most of the resistant and susceptible varieties used for the phenotypic evaluation in the present study and 
greatly important for rice breeding programs such as incorporation of blast resistant genes from one varietal back ground to an another to produce durable blast resistant varieties.

\section{ACKNOWLEDGEMENTS}

The authors thank the project Higher Education for Twenty First Century (HETC) for financial support and Plant Science Department, University of Colombo, Rice Research and Development Institute, Bathalagoda for providing necessary facilities to carry out the research work.

\section{REFERENCES}

Bryan, G.T., Jia, Y.L., Mcadams, S.A., Hershey, H.P. and Valent,B. (2000). Direct interaction of resistance genes and avirulence genes products confers rice blast resistance. EMBO. J. 19(15), 4000 - 4014.

Dissanayake, D.M.N. (1995). Genetic base of blast resistance in cultivated rice varieties in Sri Lanka and breeding strategies for durable resistance to blast. Trop. Agriculturist. 150, 1 15.

Doyle, J.J. and Doyle, J.L. (1987). Isolation of plant DNA from fresh tissue. J. Focus . 12, 13 -15 .

Fjellstrom, R., McClung, A., Shank, A.R., Marchetti, M.A., Bormans, C. and Park, W.D. (2002). Progress on development of microsatellite markers associated with rice blast resistance genes. Proceedings of the $29^{\text {th }}$ Rice Technical Working Group Meeting, Little Rock, AR, USA, 43-44.

Ghazanfar, M.K., Wakil, W. and Sahi, S.T. (2009). Influence of Various Fungicides on the Management of Rice Blast Disease. Myco. Path. 7, 29 - 34.

Guillamon, J.M., Sebate, J., Cano, J. and Querol, A. (1998). Rapid Identification of Wine Yeast species on RLFP analysis of Ribosomal ITS region. Archives of Microbiology.169 (5), $387-389$.

IRRI. (1996). Standard evaluation system for rice. $4^{\text {th }}$ ed. IRRI, Manila, Philippines.

Jayawardana,W.A.D., Jayasekera, G.A.U., Wijesundera, R.L.C. and Dissanayake, D.M.N. (2013). The phenotypic screening of rice varieties for blast resistance towards developing DNA markers linked to resistance genes. Proceedings of $69^{\text {th }}$ annual sessions of Sri Lanka Association for Advancement of Science. Part1 939/D, 69, 237.

Joshi, B.K., Parajuli, G. and Chaudhry, K. (2009). Molecular tagging, allele mining, marker breeding for blast resistance in rice. BSN-E Bulletin 1, 1 - 23.

Mackill, D.J. and Bonman, J.M. (1992). Inheritance of blast resistance in near isogenic lines of rice. J. Phytopathology. 82, $746-749$. 
McCouch, S.R, Chen, X., Panaud, O., Temnykh, S. and Xu, Y. (1997). Microsatellite marker development, mapping and applications in rice genetics and breeding. Plant Mol. Biol. 35(12), 89 - 99 .

Mithrasena, J.Y., Wijesundera, W.S.S., Wijesundera, R.L.C., Wimalasiri, D. C. and Priyanti, R.P. (2012). Pathogenic and genetic diversity of Magnaporthe oryzae population from Sri Lanka. Rice Science. 19(3), 241 - 246.

Rajapakse, R.M.T., Sandanayake, C.A. and Pathinayake, B.D. (2000). Foot prints in rice varieties improvement and its impact on rice production in Sri Lanka. In proceedings of the annual symposium of the Department of Agriculture Edited by Kotagama, H.B.,Wijesekera, G.A.W. and Wijesundara, D.S.R. Sri Lanka: Department of Agriculture.

Rossman, A.Y., Howard, R.J. and Valent, B. (1990). Pyricularia grisea, the correct name for the rice blast fungus. Mycologia. 82, 509 - 512.

Sharma, T.R., Chauhan, R.S., Singh, B.M., Sagar, V., Paul, R. and Rathour, R. (2002). RAPD and virulence analyses of Magnaporthe grisea in rice populations from north-western Himalayan region of India. J. Phytopathol. 150, 649 - 656.

Sharma, T.R., Rai, A.K., Guptha, S.K., Vijayanan, T., Devanna, B.N. and Ray ,S. (2012). Rice blast management through plant resistance: retrospect and prospect. Rev.Agri Res. DOI 10. 1007/S40003-011-0003-5.

Shikari, A.B., Khanna, A., Krishnan, S.G., Singh, U.D., Rathour, R., Tonapi, V., Sharma, T.R., Nagarajan, M., Prabhu, K.V. and Singh, A.K. (2013). Molecular analysis and phenotypic validation of blast resistance genes Pita and Pita ${ }^{2}$ in landraces of rice (Oryza sativa L.). Indian J. Genetic and Plant breeding. 73(2), 131 - 141.

Skamnioti, P. and Gurr, S.J. (2009). Against the grain-safe guarding rice from rice blast disease. J. Trends Biotechnol. 27(3), 141 - 150. 